\title{
A SUMMARY OF PERIODIC REPLACEMENT WITH MINIMAL REPAIR AT FAILURE
}

\author{
Toshio Nakagawa \\ Meijo University \\ (Received May 10, 1980; Revised January 6, 1981)
}

\begin{abstract}
Several periodic replacement policies with minimal repair at failures are summarized: 1) A policy for a unit with random and wearout failures. 2) Two modified policies where if a failure occurs just before the replacement. time, then (i) a unit remains failed, (ii) a unit is replaced by a new one. 3) Three imperfect preventive maintenance (pm) policies where (i) a unit after pm has the same failure rate as before pm with a certain probability, (ii) the age of a unit becomes $x$ units of time younger at pm, (iii) the age of a unit after pm reduces to at at pm. Expected cost rates for each model are obtained and optimum policies are discussed. Some examples for the above models are presented.
\end{abstract}

\section{Introduction}

Barlow and Hunter [1] considered the following replacement policy: A unit is replaced periodically at scheduled times $k T(k=1,2, \ldots)$. After each failure, only minimal repair is made so that the failure rate remains undisturbed by any repair of failures between successive replacements. This policy is commonly used with complex systems such as computers and airplanes. Holland and McLean [6] provided a practical procedure for applying the policy to large motors and small electrical parts. Morimura [8] has modified the policy in the way of the version that a unit is replaced at the $k^{\text {th }}$ failure and the $(k-1)^{\text {th }}$ previous failures are corrected with minimal repair. Further, Tilquin and Cléroux [17] introduced the adjustment costs which increase with the age of a unit. Tahara and Nishida [15] also introduced the breakdown cost suffered for a failed unit which is replaced at the first failure after some age.

In this paper, we summarize the known results of the policy, and consider extended and modified models which could be applicable to practical fields. For instance, we consider the policy for a used unit of age $x$ and for a unit 
with random and wearout failures, and a discrete time policy where a unit operates at discrete times. Further, we consider two modifications of the policy in which any failed unit just before the scheduled replacement undergoes no repair. Finally, three imperfect preventive maintenance models with minimal repair at failures are presented. We discuss optimum policies which minimize the expected cost rates for each model. Some useful remarks for optimum policies are further made.

\section{Known Results and Remarks}

A unit is replaced at scheduled times $k T(k=1,2, \ldots)$ and any unit is as good as new after replacement. Only minimal repair is made when the unit fails between periodic replacements. So that, the failure rate of the unit remains undisturbed by any repair of failures. Assume that the repair and replacement times are negligible.

Suppose that the failure times of each unit are independent, and have a density $f(t)$ and a distribution $F(t)$. Then, the following results were obtained by $[2, p .96]$ : The expected cost rate is

$$
C(T)=\frac{c_{1} \int_{0}^{T} r(t) d t+c_{2}}{T},
$$

where $r(t)=$ failure rate of the failure time distribution $F(t)$, i.e., $r(t) \equiv$ $f(t) / \bar{F}(t)$ where $\bar{F} \equiv 1-F$,

$\mathrm{c}_{1}=$ cost of minimal repair,

$c_{2}=$ cost of scheduled replacement.

The purpose is to seek an optimum replacement time $T^{*}$ which minimizes the expected cost rate $C(T)$. Differentiating $C(T)$ with respect to $T$ and setting it equal to zero imply

$$
\operatorname{Tr}(T)-\int_{0}^{T} r(t) d t=\mathrm{c}_{2} / \mathrm{c}_{1}
$$

Suppose that the failure rate $r(t)$ is monotonely increasing. Then, if a solution $T^{*}$ to $(2.2)$ exists, it is unique, and the resulting cost is

$$
C\left(T^{*}\right)=c_{1} r\left(T^{*}\right) \text {. }
$$

Further, equation (2.2) can be rewritten as

(2.2 $\left.{ }^{\prime}\right) \quad s_{0}^{T} t d r(t)=c_{2} / c_{1}$.

Thus, if $\int_{0}^{\infty} t d r(t)>c_{2} / c_{1}$ then there exists a solution to (2.2). 
Remarks

(i) Suppose that $r(t)$ is monotonely increasing. Then, the optimum time $T^{*}$ is not greater than that of the standard age replacement model [2, p. 85] in which the expected cost rate is

$$
C_{\mathrm{A}}(T)=\frac{c_{1} F(T)+c_{2}}{\int_{0}^{T} \bar{F}(t) d t},
$$

and the optimum time is given by a solution of the equation

$$
r(T) \int_{0}^{T} \vec{F}(t) d t-F\left(T^{\prime}\right)=c_{2} / c_{1} .
$$

For, we easily have the inequality

$$
\int_{0}^{T}[r(T)-r(t)] F(t) d t \geq 0
$$

since $r(t)$ is increasing. Therefore

$$
T r(T)-\int_{0}^{T} r(t) d t \geq r(T) \int_{0}^{T} \bar{F}(t) d t-F(T) .
$$

(ii) When we adopt the total expected cost as an appropriate objective function for an infinite time span, we should evaluate values of all future costs by using a discount rate. We apply the continuous discounting to the costs at the times when these costs occur actually. Let $\alpha$ be a positive discount rate and $C(T ; \alpha)$ be the total expected cost for the policy. In this case, equations (2.1), (2.2), and (2.3) are rewritten, respectively, as follows:

$$
C(T ; \alpha)=\frac{c_{1} \int_{0}^{T} e^{-\alpha t} r(t) d t+c_{2} e^{-\alpha T}}{1-\mathrm{e}^{-\alpha T}},
$$

$$
\begin{aligned}
& \frac{1-e^{-\alpha T}}{\alpha} r(T)-\int_{0}^{T} e^{-\alpha t} r(t) d t=\frac{c_{2}}{c_{1}}, \\
& C\left(T^{*} ; \alpha\right)=\left(c_{1} / \alpha\right) r\left(T^{*}\right)-c_{2} .
\end{aligned}
$$

Note that $\lim \alpha C(T ; \alpha)=C(T)$ which is the expected cost rate without discounting. $\alpha \rightarrow 0$

(iii) Consider a system consisting of $n$ identical units which operate independently each other. Assume that all together are replaced at times $k T(k=$ $1,2, \ldots)$ and each failed unit between replacements undergoes minimal repair. Then, the expected cost rate is

$$
C(T ; n)=\frac{n \mathrm{c}_{1} \int_{0}^{T} r(t) d t+\mathrm{c}_{2}}{T},
$$


where $c_{1}=$ cost of minimal repair for one failed unit,

$c_{2}=$ cost of scheduled replacement for all units.

(iv) Consider the same policy for a used unit. A unit is replaced at times KT by the same used unit of age $x$, where $x$ is previously specified. Then, the expected cost rate is, from [12],

$$
C(T ; x)=\frac{c_{1} \int_{x}^{T+x} r(t) d t+c_{2}(x)}{T},
$$

where $c_{2}(x)=$ acquisition cost of a used unit of age $x$. In this case, equations $(2.2)$ and $(2.3)$ are rewritten as

$$
\begin{aligned}
& \operatorname{Tr}(T+x)-\int_{x}^{T+x} r(t) d t=c_{2}(x) / c_{1}, \\
& C\left(T^{*} ; x\right)=c_{1} r\left(T^{*}+x\right) .
\end{aligned}
$$

Next, consider the problem that it is the most economical to use a unit of what is the age. Suppose that $x$ is a variable and inversely, $T$ is constant, and $c_{2}(x)$ is differentiable. Then, differentiating $C(T ; x)$ with respect to $x$ and setting it equal to zero imply

$$
r(T+x)-r(x)=-c_{2}^{\prime}(x) / c_{1}
$$

which is a necessary condition that a finite $x$ minimizes $C(T ; x)$ for a fixed $T$. (v) Consider a unit which operates at discrete times $n(n=1,2, \ldots)$. The unit is replaced at times $k N(k=1,2, \ldots)$ and any failed unit between replacements undergoes minimal repair. Note that $N$ corresponds to $T$ in the continuous time model. Let $\left\{p_{n}\right\}_{n=1}^{\infty}$ denote the discrete failure distribution that the unit fails at time $n$. Then, the expected cost rate is

$$
C(N)=\frac{c_{1}^{N} \sum_{n=1}^{N} r(n)+c_{2}}{N} \quad(N=1,2, \ldots),
$$

where $r(n)$ = failure rate of the discrete failure distribution, i.e., $r(n) \equiv$

$$
p_{n} \sum_{j=n}^{\infty} p_{j}(n=1,2, \ldots) \text {. }
$$

We can convert the known results in continuous case to the discrete mode]. as follows: From the two inequalities $C(N+1) \geq C(N)$ and $C(N)<C(N-1)(N=$ $1,2, \ldots)$, we have, respectively,

$$
L(N) \geq \mathrm{c}_{2} / \mathrm{c}_{1} \text { and } L(N-1)<c_{2} / c_{1}
$$

where 


$L(N)= \begin{cases}N r(N+1)-\sum_{n=1}^{N} r(n) & (N=1,2, \ldots), \\ 0 & (N=0) .\end{cases}$

It is easily seen that if $r(n)$ is monotonely increasing then $L(N)$ is monotonely increasing. Thus, if a solution $N^{*}$ to $(2.16)$ exists, it is unique and minimizes the expected cost rate $C(N)$.

\section{Example}

Suppose that the failure time distribution is a discrete Weibull with a shape parameter 2, i.e., $p_{n}=q^{(n-1)^{2}}-q^{n^{2}}(n=1,2, \ldots ; 0<\mathrm{q}<1)$ (see [14]). Then, we have $r(n)=1-\mathrm{q}^{2 n-1}(n=1,2, \ldots)$, which is monotonely increasing from 1 - q to 1 . From (2.16), an optimum replacement time $N^{*}$ is given by a maximum of $N$ which satisfies

$$
\frac{\mathrm{q}}{1-\mathrm{q}^{2}}\left\{1-\left[1+N\left(1-\mathrm{q}^{2}\right)\right] \mathrm{q}^{2 N}\right\} \geq \frac{\mathrm{c}_{2}}{\mathrm{c}_{1}} \text {. }
$$

For example, if $q=0.95$ then we have $N^{*}=2,4,5,8,11,14,17$ for each $c_{2} / c_{1}=0.1,0.5,1.0,2.0,3.0,4.0,5.0$, respectively.

\section{Replacement Policy with Random and Wearout Failures}

Mine and Kawai [7] considered a modified replacement policy for a unit with random and wearout failures, where an operating unit enters a wearout failure period at a fixed time $T_{0}$, after it has operated continuously in a random failure period. We assume that the unit is replaced at scheduled time $T+T_{0}$, where $T_{0}$ is constant and previously given, and it undergoes only minimal repair at failures between replacements.

Suppose that the unit has a constant failure rate $\lambda$ in a random failure period and $\lambda+r(t)$ in a wearout failure period. Then, the expected cost rate is given by

$$
c_{1}\left(T ; T_{0}\right)=c_{1} \lambda+\frac{c_{1} \delta_{0}^{T} x(t) d t+c_{2}}{T+T_{0}} .
$$

Thus, if $r(t)$ is monotonely increasing and there exists a solution $T^{*}$ which satisfies

$$
\left(T+T_{0}\right) r(T)-\int_{0}^{T} r(t) d t=c_{2} / c_{1},
$$


then it is unique and the resulting cost is

$$
C_{1}\left(T^{*} ; T_{0}\right)=c_{1}\left[\lambda+r\left(T^{*}\right)\right]
$$

Further, it is easy to see that $T^{*}$ is a decreasing function of $T_{0}$ since the left-hand side of (3.2) is increasing in $T_{0}$ for a fixed $T$. Thus, an optimum time $T^{*}$ is less than the optimum time given by (2.2).

\section{Modified Replacement Policies}

Suppose that the unit fails just before one of the scheduled replacement times. Then, it may be wasteful to repair the failed unit and may be wise to replace it at the next scheduled replacement. That is, if a failure occurs in an interval $\left(k T-T_{d}, k T\right)\left(0 \leq T_{d} \leq T\right)$, the unit is not repaired in this interval and is replaced at scheduled time $k T$. The unit will be down for the time interval from its failure to the replacement. Cox [4] considered a similar model of block replacement where the replacement of a failed unit just before the scheduled time is postponed untill the next scheduled replacement.

The mean time between failure and its replacement when a failure occurs in an interval $\left(T-T_{\mathrm{d}}, T\right)$ is

$$
\frac{\int_{T-T_{\mathrm{d}}}^{T}(T-t) d F(t)}{\bar{F}\left(T-T_{\mathrm{d}}\right)}=\frac{\int_{T-T_{\mathrm{d}}}^{T}\left[F(t)-F\left(T-T_{\mathrm{d}}\right)\right] d t}{\bar{F}\left(T-T_{\mathrm{d}}\right)} .
$$

Thus, the expected cost rate is

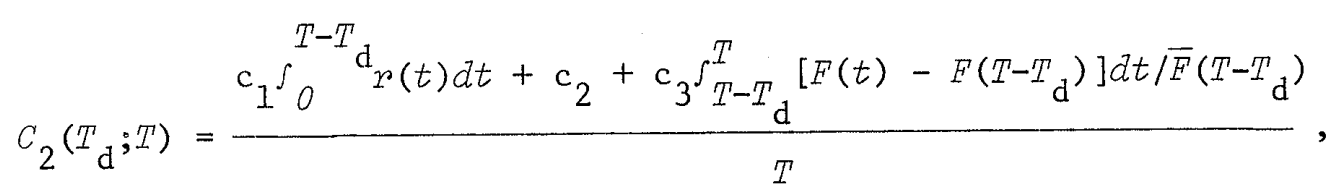

$$
\begin{aligned}
\text { where } c_{3}= & \text { cost of the time elapsed between failure and its replacement per } \\
& \text { unit of time. }
\end{aligned}
$$

Suppose that a constant $T$ minimizes the expected cost rate $C(T)$ in $(2.1)$, i.e., $T$ is a solution of equation (2.2). Then, differentiating $C_{2}(T$; $T$ ) with respect to $T_{\mathrm{d}}$ and setting it equal to zero for a fixed $T>0$, we have

$$
\frac{\int_{T-T_{\mathrm{d}}}^{T} \bar{F}(t) d t}{\bar{F}\left(T-T_{\mathrm{d}}\right)}=\frac{\mathrm{c}_{1}}{\mathrm{c}_{3}} .
$$

Thus, if $r(t)$ is monotonely increasing and $s_{0}^{T} \bar{F}(t) d t>c_{1} / c_{3}$, then there exists a unique $T_{\mathrm{d}}^{*}$ which satisfies $(4.2)$, and $T_{\mathrm{d}}^{*}$ is an increasing function of T. Conversely, if $\int_{0}^{T} \bar{F}(t) d t \leq c_{1} / c_{3}$, then $T_{\mathrm{d}}^{*}=T$, i.e., a failed unit is not 
repaired and is replaced only at scheduled time, and

$$
C_{2}(T ; T)=\frac{c_{2}+c_{3} \int_{0}^{T} F(t) d t}{T} .
$$

In the above policy, it may be wise to replace a failed unit at scheduled time without repairing, but we can not sometimes leave a failed unit as it is until the scheduled replacement time. To overcome this, we consider the following model: If the unit fails in an interval ( $\left.T-T_{d} ; T\right)$ then it is replaced by a new one before a scheduled replacement time. Tahara and Nishida [14] called the policy as the $(t, T)$-policy.

The expected cost rate is, from [15]

$$
C_{3}\left(T_{\mathrm{d}} ; T\right)=\frac{c_{1} \int_{0}^{T-T_{\mathrm{d}}} r(t) d t+c_{2}+c_{4}\left[F(T)-F\left(T-T_{\mathrm{d}}\right)\right] / \bar{F}\left(T-T_{\mathrm{d}}\right)}{T-T_{\mathrm{d}}+\int_{T-T_{\mathrm{d}}}^{T} \bar{F}(t) d t / \bar{F}\left(T-T_{\mathrm{d}}\right)},
$$

where $c_{4}=$ additional replacement cost caused by failure. Note that $C_{3}(T ; T)$ agrees with [2, p. 87], which is the expected cost of the standard age replacement mode1.

Suppose that $c_{2}+c_{4}>c_{1}>c_{4}$ and $r(t)$ is monotonely increasing. Then, by the method similar to the one of [15], the following results are obtained: There exists a unique $T_{\mathrm{d}}^{*}\left(0<T_{\mathrm{d}}^{*}<T\right)$ which satisfies

$$
c_{1}\left[\frac{\left(T-T_{\mathrm{d}}\right) \bar{F}\left(T-T_{\mathrm{d}}\right)}{\int_{T-T_{\mathrm{d}}}^{T} \bar{F}(t) d t}-\int_{0}^{T-T_{\mathrm{d}}} r(t) d t\right]-c_{4} \frac{\left(T-T_{\mathrm{d}}\right) \bar{F}(T)}{\int_{T-T_{\mathrm{d}}}^{T} \bar{F}(t) d t}=c_{2}+c_{4}-c_{1} \text {, }
$$

and the resulting minimum cost is

$$
C_{3}\left(T_{\mathrm{d}}^{*} ; T\right)=\frac{\mathrm{c}_{1} \overline{\bar{F}}\left(T-T_{\mathrm{d}}^{*}\right)-\mathrm{c}_{4} \bar{F}(T)}{\int_{T-T_{\mathrm{d}}^{*}}^{*} \bar{F}(t) d t} .
$$

Further, if $c_{1} \leq c_{4}$ then $T_{\mathrm{d}}^{*}=0$, viz., the unit undergoes only minimal repair until the scheduled replacement, and we have $C_{3}(0 ; T)=C(T)$. If $c_{1}>$ $c_{2}+c_{4}$ then $T_{d}^{*}=T$, viz., the unit is replaced at failure or at time $T$, whichever occurs first, after its installation, and

$$
C_{3}(T ; T)=\frac{c_{2}+c_{4} F^{\prime}(T)}{s_{0}^{T} \bar{F}(t) d t} .
$$

Example

Suppose that the failure time distribution is a gamma distribution with 
a shape parameter 2, i.e., $F(t)=1-(1+t) \mathrm{e}^{-t}$. Then, the failure rate is $t /(1+t)$ and is monotonely increasing from 0 to 1 . Table 1 shows the optimum replacement time $T^{*}$ which minimizes $C(T)$ in $(2.1)$ for $c_{1}=2,4,6,8,10,15$, 20 when we assume that $c_{2}=5, c_{3}=15$, and $c_{4}=4$. Further, when we put $T=$ $T^{*}, T^{*}-T_{\mathrm{d}}^{*}, C_{2}\left(T_{\mathrm{d}}^{*} ; T^{*}\right)$, and $T^{*}-T_{\mathrm{d}}^{*}, T_{3}\left(T_{\mathrm{d}}^{*} ; T^{*}\right)$ are computed. It has been shown that both $T^{*}-T_{\mathrm{d}}^{*}$ are decreasing in the minimal repair cost $c_{1}$, but the expected cost rates are increasing in $c_{1}$.

Table 1. Dependence of the minimal repair cost $c_{1}$ in $T^{*}, C\left(T^{*}\right), T^{*}-T_{d}^{*}$, $C_{2}\left(T_{\mathrm{d}}^{*} ; T^{*}\right)$, and $T^{*}-T_{\mathrm{d}}^{*}, C_{3}\left(T_{\mathrm{d}}^{*} ; T^{*}\right)$ when $c_{2}=5, c_{3}=15$, and $c_{4}=4$

\begin{tabular}{rrrcccc}
\hline minimal repair & $T^{*}$ & $C\left(T^{*}\right)$ & $T^{*}-T_{\mathrm{d}}^{*} C_{2}\left(T_{\mathrm{d}}^{*} ; T^{*}\right)$ & $T^{*}-T_{\mathrm{d}}^{*} C_{3}\left(T_{\mathrm{d}}^{*} ; T^{*}\right)$ \\
\hline 2 & 31.1 & 1.94 & 31.0 & 1.93 & 31.1 & 1.94 \\
4 & 7.4 & 3.52 & 7.1 & 3.46 & 7.4 & 3.52 \\
6 & 4.2 & 4.84 & 3.7 & 4.58 & 1.4 & 4.37 \\
8 & 2.9 & 5.97 & 2.3 & 5.35 & 0.3 & 4.69 \\
10 & 2.3 & 6.99 & 1.5 & 5.84 & 0 & 4.88 \\
15 & 1.6 & 9.16 & 0.3 & 6.15 & 0 & 5.46 \\
20 & 1.2 & 11.03 & 0 & 6.19 & 0 & 6.05 \\
\hline
\end{tabular}

\section{Imperfect Preventive Maintenance Policies}

Barlow and Hunter [1] considered the preventive maintenance (pm) policy in which a failed unit between periodic pm's undergoes minimal repair. Earlier results of optimum pm policies have been summarized in [9]. However, almost all models have assumed that a unit is as good as new after any pm. In practice, this assumption is often not true: A unit after pm usually might be younger at pm, and occasionally might be worce than before pm because of faulty procedures.

In this section, we consider the following three imperfect pm policies for a unit with minimal repair at failures:

(i) A unit after pm has the same failure rate as before pm or is as good as new with certain probabilities.

(ii) The age of a unit becomes $x$ units of time younger at each pm.

(iii) The age of a unit after pm reduces to at when it was $t$ before $\mathrm{pm}$. Assume that the unit is maintained preventively at scheduled times $k T$ 
$(k=1,2, \ldots)$, and undergoes only minimal repair at failures between pm's. Further, assume that the repair and pm times are negligible.

\section{(i) Model $\mathrm{A}$}

Suppose that the unit after pm has the same failure rate as it has been before pm with probability $p(0 \leq p<1)$ and is as good as new with probability $\bar{p}(\equiv 1-p)$. The pm action does not make any improvement in the condition of the unit with probability $p$, because of wrong adjustments, bad parts, damage done during pm, and so on. Helvic [5] applied such an imperfect pm to the periodic maintenance of fault tolerant computing systems. The expected cost rate is, from [10],

$$
C_{4}(T ; p)=\frac{c_{1}(\bar{p})^{2} \sum_{j=1}^{\infty} p^{j-1} \int_{0}^{j T} r(t) d t+c_{2}}{T},
$$

where $c_{1}=$ cost of minimal repair,

$c_{2}=$ cost of scheduled pm.

Suppose that $r(t)$ is monotonely increasing. Then, if $\int_{0}^{\infty} t d r(t)>c_{2} /$ $\left[c_{1}(\bar{p})^{2}\right]$ then there exists a finite and unique $T^{*}$ which satisfies

$$
\sum_{j=1}^{\infty} p^{j-1} j_{0}^{j T} t d r(t)=c_{2} /\left[c_{1}(\bar{p})^{2}\right],
$$

and the resulting cost is

$$
C_{4}\left(T^{*} ; p\right)=c_{1}(\bar{p})^{2} \sum_{j=1}^{\infty} p^{j-1} j r(j T) .
$$

(ii) Model B

Suppose that the age of the unit becomes $x$ units of time younger at each pm. where $x(0 \leq x \leq T)$ is constant and previously specified. Further, suppose that the unit is replaced if it operates for the time interval NT where $N$ is a positive integer. Then, the expected cost rate is easily given by

$$
C_{4}(T, N ; x)=\frac{c_{1} \sum_{j=0}^{N-1} j_{j(T-x)}^{T+j(T-x)} r(t) d t+(N-1) c_{2}+c_{3}}{N T},
$$

where $c_{3}=$ cost of scheduled replacement at time NT, where $c_{3}>c_{2}$.

Suppose that $N$ is constant and $T$ is a variable on $(0, \infty)$. A necessary condition that a finite $T^{*}$ minimizes $C_{4}(T, N ; x)$ is that it satisfies

$$
\sum_{j=0}^{N-1} \int_{j(T-x)}^{T+j(T-x)} \operatorname{tdr}(t)=\frac{(N-1) c_{2}+c_{3}}{c_{1}} .
$$


Next, suppose that: $T$ is constant. Further, $C_{4}(T, 0 ; x)=\infty$ formally for simplicity of analysis. Then, a necessary condition that there exists a finite and unique $N^{*}$ which minimizes $C_{4}(T, N ; x)$ is that $N^{*}$ satisfies $C_{4}(T, N+1 ; x)$ $\geq C_{4}(T, N ; x)$ and $C_{4}(T, N ; x)<C_{4}(T, N-1 ; x)(N=1,2, \ldots)$. Thus, from these inequalities, we have, respectively,

$$
L(N ; x) \geq\left(c_{3}-c_{2}\right) / c_{1} \text { and } L(N-1, x)<\left(c_{3}-c_{2}\right) / c_{1} \quad(N=1,2, \ldots),
$$

where

$$
L(N ; x) \equiv \begin{array}{cc}
N f_{N(T-x)}^{T+N(T-x)} r(t) d t-\sum_{k=0}^{N-1} \int_{k(T-x)}^{T+k(T-x)} r(t) d t \quad(N=1,2, \ldots), \\
0 & (N=0) .
\end{array}
$$

Further, we have

$$
L(N+1 ; x)-L(N ; x)=(N+1)\left[\int_{(N+1)(T-x)}^{T+(N+1)(T-x)} r(t) d t-\int_{N(T-x)}^{T+N(T-x)} r(t) d t\right] .
$$

Thus, if $r(t)$ is monotonely increasing, then $L(N ; x)$ is also an increasing function of $N$ from (5.7). Therefore, if $L(\infty ; x) \geq\left(c_{3}-c_{2}\right) / c_{1}$ then an optimum number $N^{*}$ of pm cycles is given by a minimum value of $N$ which satisfies $L(N ; x)$ $\geq\left(c_{3}-c_{2}\right) / c_{1}$, and otherwise, we make no replacement.

\section{(iij) Model $\mathrm{C}$}

Suppose that the age of the unit after pm reduces to $a t(0 \leq \alpha \leq 1)$ when it was $t$ before pm, i.e., the age becomes $t(1-a)$ units of time younger at each pm. Then, the expected cost rate is

$$
C_{4}(T, N ; a)=\frac{\left.c_{1} \sum_{k=0}^{N-1} \int_{k} A_{k} T+1\right) T}{N(t) d t+(N-1) c_{2}+c_{3}} \text {, }
$$

where $A_{k} \equiv a+a^{2}+\ldots+a^{k}(k=1,2, \ldots)$, and $A_{0} \equiv 0$.

We can have similar results to ones of Model B: Equations (5.5) and $L(N ; \alpha)$ are rewritten as, respectively,

$$
\begin{aligned}
& \sum_{k=0}^{N-1} \int_{A_{k} T}^{\left(A_{k}+1\right) T} t d r(t)=\frac{(N-1) c_{2}+c_{3}}{c_{1}} \\
& L(N ; \alpha)=N \int{ }_{A_{N} T}^{\left(A_{N}+1\right) T} r(t) d t-\sum_{k=0}^{N-1} \int A_{A_{k} T}^{\left(A_{k}+1\right) T} r(t) d t \quad(N=1,2, \ldots) .
\end{aligned}
$$

It is noted that all models are identical and agree with Section 2 when $p=0$ in Model A, $N=1$ and $x=T$ in Model $\mathrm{B}$, and $N=1$ and $a=0$ in Model C. 
Example

Suppose that the failure time has a Weibull distribution with a shape parameter $\beta$, i.e., $F(t)=1-\exp \left(-\lambda t^{\beta}\right)(\lambda>0, \beta>1)$. Then, the failure rate is $r(t)=\lambda \beta t^{\beta-1}$, which is monotonely increasing, taking the values from 0 to $\infty$. Thus, we have the following results for each model.

(i) Model A

The expected cost rate is, from (5.1),

$$
C_{4}(T ; p)=\frac{c_{1} \bar{p} \lambda T^{\beta} g(\beta)+c_{2}}{T}
$$

where $g(\beta) \equiv \bar{p} \sum_{i}^{\infty} p^{j-1_{j} \beta}$ which represents the $\beta^{\text {th }}$ moment of the geometric distribution with $\overline{\bar{h}}^{1}$ parameter $p$. The optimum pm time is, from (5.2),

$$
T^{*}=\left[\frac{c_{2}}{c_{1} \overline{p \lambda}(\beta-1) g(\beta)}\right]^{1 / \beta} .
$$

(ii) Mode1 B

The expected cost rate is, from (5.4),

$$
C_{4}(T, N ; x)=\frac{c_{1} \lambda \sum_{k=0}^{N-1}\left\{[T+k(T-x)]^{\beta}-[k(T-x)]^{\beta}\right\}+(N-1) c_{2}+c_{3}}{N T} .
$$

From (5.5),

$$
\sum_{j=0}^{N-1}\left\{[T+j(T-x)]^{\beta}-[j(T-x)]^{\beta}\right\}=\frac{(N-1) c_{2}+c_{3}}{c_{1} \lambda(\beta-1)},
$$

where the left-hand side is monotonely increasing in $T$, taking the values from 0 to $\infty$. Thus, the optimum pm time $T^{*}$ exists uniquely, which satisfies (5.5). Further, the left-hand side is also decreasing in $x$ for a fixed $T$, and hence, the optimum pm time $T^{*}$ is an increasing function of $x$. Thus, putting $x=0$ and $x=T$ in (5.5), we have the lower and upper limits:

$$
\frac{1}{N}\left[\frac{(N-1) c_{2}+c_{3}}{c_{1} \lambda(\beta-1)}\right]^{1 / \beta} \leq T^{*} \leq\left[-\frac{1}{N} \frac{(N-1) c_{2}+c_{3}}{c_{1} \lambda(\beta-1)}\right]^{1 / \beta} .
$$

(iii) Model C

The expected cost rate is, from (5.8),

$$
C_{4}(T, N ; \alpha)=\frac{c_{1} \lambda \sum_{k=0}^{N-1} T^{\beta}\left[\left(A_{k}+1\right)^{\beta}-A_{k}^{\beta}\right]+(N-1) c_{2}+c_{3}}{N T},
$$

and the optimum pm time $T^{*}$ exists uniquely, which satisfies 


$$
\sum_{k=}^{N-1} T^{\beta}\left[\left(A_{k}+1\right)^{\beta}-A_{k}^{\beta}\right]=\frac{(N-1) c_{2}+c_{3}}{c_{1} \lambda(\beta-1)} .
$$

Until now, we have assumed in Models B \& $\mathrm{C}$ that $x$ and $\alpha$ are constant. Actually, these would depend on the cost or the time spent for pm. To take one example, it is supposed in Model $C$ that the age of the unit after pm decreases in proportion to cost or time for $\mathrm{pm}$. Then, some simple functions of a are: (1) $a=1-\left(c_{2} / c_{3}\right)$ for $0<c_{2} \leq c_{3},(2) a=\exp \left(-\theta c_{2}\right)$ for $\theta>0, c_{2}$ $>0$, (3) $a=\exp (-\theta y)$ for $\theta>0$, where $y$ is the time taken for pm. Other functions could be formed by the resources consumed in pm. When $a=\exp (-\theta y)$, $A_{k}$ in (5.8) is given by

$$
A_{k}=\frac{\exp (-\theta y)-\exp [-\theta(k+1) y]}{1-\exp (-\theta y)} .
$$

In particular, if we take sufficient time for pm, i.e., $y \rightarrow \infty$, then $C_{4}(T, N ; \alpha)$ $=C(T)$ in (2.1). Inversely, if we take no time for pm, i.e., $y \rightarrow 0$ then

$$
C_{4}(T, N ; \alpha)=\frac{c_{1} \int_{0}^{N T} r(t) d t+c_{3}}{N T} \text {. }
$$

Similar discussions are made for Model B.

\section{Concluding Remarks}

We have summarized the periodic replacement models with minimal repair at failures. In particular, three imperfect pm models are theoretically new and could be applied to more practical fields. Throughout this paper, we have assumed that the failure rate remains undisturbed by any repair of failures between replacements. Actually, this assumption is often not true. It is usually said that the unit after minimal repair might be worce than before failure.

Suppose that the age of the unit after minimal repair becomes $\alpha t(\alpha \geq 0)$ when it was $t$ before failure. If $a<1$ then the unit is younger at minimal repair and if $a>1$ then it is worce than before failure. Then, the expected number of failures during the interval $(0, T]$ is easily given by

$$
M(T ; a)=\sum_{k=1}^{\infty} \int_{t_{1}<t_{2}<\ldots<t_{k-}<T} \frac{f\left(a t_{1}+t_{2}-t_{1}\right)}{\bar{F}\left(a t_{1}\right)} \frac{f\left[\alpha^{2} t_{1}+a\left(t_{2}-t_{1}\right)+t_{3}-t_{2}\right]}{\bar{F}\left[a^{2} t_{1}+a\left(t_{2}-t_{1}\right)\right]}
$$




$$
\ldots \frac{f\left[a^{k-1} t_{1}+a^{k-2}\left(t_{2}-t_{1}\right)+\ldots+a\left(t_{k-1}-t_{k-2}\right)+t_{k}-t_{k-1}\right]}{\bar{F}\left[a^{k-1} t_{1}+a^{k-2}\left(t_{2}-t_{1}\right)+\ldots+a\left(t_{k-1}-t_{k-2}\right)\right]} d t_{1} d t_{2} \ldots d t_{k} .
$$

It is evident that

$$
\begin{aligned}
& M(T ; 0)=M(T), \\
& M(T ; I)=\int_{0}^{T} r(t) d t,
\end{aligned}
$$

where $M(t)=$ renewal function of the failure time distribution $F(t)$, i.e.,

$$
\begin{aligned}
& M(t) \equiv \sum_{k=1}^{\infty} F^{(k)}(t) \text { where } F^{(k)} \text { is the k-fold convolution of } F(t) \\
& \text { with itself. }
\end{aligned}
$$

Thus, the expected cost rate is

$$
C(T ; \alpha)=\frac{\mathrm{c}_{1} M(T ; \alpha)+\mathrm{c}_{2}}{T} .
$$

When $a=0$, the unit becomes always new at each minimal repair and the model corresponds to block replacement. When $a=1$, the failure rate is not disturbed by each minimal repair and this corresponds to the model in this paper. However, in general, it is very difficult to make discussions about optimum policies for the model.

We have not treated block replacement appeared in $[3,4,16]$. The po1icies in this paper could be applied to other replacement models. For instance, we can combine a block replacement policy and this policy. That is, a failed unit is replaced by a new one during $\left(0, T-T_{\mathrm{d}}\right]$ and undergoes minimal repair during $\left(T-T_{\mathrm{d}}, T\right)$ for $0 \leq T_{\mathrm{d}} \leq T$. Then, the expected cost rate is, from [11],

$$
\left.c_{1}\left\{\bar{F}\left(T-T_{\mathrm{d}}\right) \int_{T-T_{\mathrm{d}}}^{T} r(t) d t+\int_{0}^{T-T} \mathrm{~d}_{\left[\int_{T-T}\right.}^{T} r(t-u) d t\right] \bar{F}\left(T-T_{\mathrm{d}}-u\right) d M(u)\right\}
$$

$$
C_{5}\left(T_{\mathrm{d}} ; T\right)=\frac{+c_{2}+c_{5} M\left(T-T_{d}\right)}{T}
$$

where $c_{5}=$ cost of replacement for a failed unit. 


\section{References}

[1] Barlow, R.E. and Hunter, L.C.: Optimum Preventive Maintenance Policies. Operations Research, Vo1.8, No.1 (1960), 90-100.

[2] Barlow, R.E. and Proschan, F.: Mathematical Theory of Reliability. John Wiley \& Sons, New York, 1965.

[3] Berg, M. and Epstein, B.: A Modified Block Replacement Policy. Naval Research Logistics Quarterly, Vo1.23, No.1 (1976), 15-24.

[4] Cox, D.R.: Renewal Theory. Methuen, London, 1963.

[5] Helvic, B.E.: Periodic Maintenance on the Effect of Imperfectness. Proceedings of 2980 . International Symposium on Fault-Tolerant Computing. 1980, 204-206.

[6] Holland, C.W. and McLean, R.A.: Applications of Replacement Theory. AIIE Trans., Vo1.7, No.1 (1975), 42-47.

[7] Mine, H. and Kawai, H.: Preventive Replacement of a 1-unit System with a Wearout State. IEEE Irans. on Reliability, Vol.R-23, No.1 (1974), 24-28.

[8] Morimura, H.: On Some Preventive Maintenance Policies for IFR. $J$. Operations Research Soc. of Japan, Vo1.12, No.3 (1970), 94-124.

[9] Nakagawa, T.: Optimum Preventive Maintenance Policies for Repairable Systems. IEEE Trans. on Reliability, Vol.R-26, No.3 (1977), 168-173.

[10] Nakagawa, T.: Optimum Policies When Preventive Maintenance is Imperfect. IEEE Trans. On Reliability, Vo1.R-28, No.4 (1979), 331-332.

[11] Nakagawa, T.: A Summary of Block Replacement Policies. R.A.I.R.O. Recherche Opérationnelle, Vo1.13, No.4 (1979), 351-361.

[12] Nakagawa, T.: Optimum Replacement Policies for a Used Unit. J. Operations Research Soc. of Japan, Vol.22, No.4 (1979), 338-346.

[13] Nakagawa, T.: A Summary of Imperfect Preventive Maintenance Policies with Minimal Repair. R.A.I.R.O. Recherche Opérationnelle, Vol.14, No.3 (1980), 249-255.

[14] Nakagawa, T. and Osaki, S.: The Discrete Weibull Distribution. IEEE Trans. on Reliability, Vo1.R-24, No.5 (1975), 300-301.

[15] Tahara, A. and Nishida, T.: Optimal Replacement Policy for Minima1 Repair Mode1. J. Operations Research Soc. of Japan, Vo1.18, No.3 \& 4 (1975), 113-124.

[16] Tango, T.: A Modified Block Replacement Policy Using Less Reliable Items. IEEE Trans. On Reliability, Vol.R-28, No.5 (1979), 400-401. 
[17] Tilquin, C. and Cléroux, R.: Periodic Replacement with Minimal Repair at Failure and Adjustment Costs. Naval Research Logistics Quarterly, Vo1.22, No.2 (1975), 243-254.

Toshio NAKAGAWA: Department of Mathematics, Faculty of Science and Engineering, Meijo University, Tenpaku-cho, Tenpaku-ku, Nagoya, 468, Japan. 
ユニットが故障したとき，小修理を行ない，その修理によって故障率が変わらないユニットの定期 取替方策を考える。このような方策はコンピュータなどの複雑なンステムや電子部品などの取替に応 用されて扣り，理論的にも多くの研究者が興味をむって扱っている。

ここでは, 今迄に得られている結果のまとめと(i)年令による取替方策との比較, (ii)割引率を考慮し た場合，(iii) n 個のユニット，(IV)中古コニット，(V)離散型の場合，に拡張し，それぞれ最適方策を議論 する。

さらに，このモデルを修正・補正した次の 3 つのモデルを考える。

1. 偶発故障と劣化故障を伴うユニットに対する取替方策。

2. 取替時刻の直前に故障したとき（i)そのまま取替時刻まで放置する，(ii)新しいユニットに早く取 替觉る，2つの補正された取替方策。

3. (i)ある確率で予防保全が失敗する，(ii)予防保全によって $x$ 才若返える，(ii)予防保全によってある 率だけ若返える，3つの不完全予防保全方策。

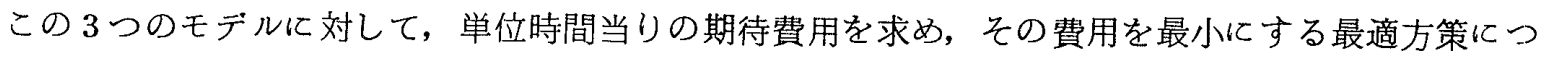
いて議論する。ある適当な条件のもとで, 最適取替時間が方程式の唯一の解として求められることが 示され，その結果に対する考察が加えられる。また，結果の内容を理解し易くするため，故障分布が ワイブル分布に従う場合などの例題が適宜に与えられている。

最後に，このモデルを実際的に修正したモデルで，小修理によって故障率が変わる場合とこの方策 とブロック取替を合併した場合が簡単に述べられる。 